\title{
Oxygen pore water profiles in continental shelf sediments of the North Sea: turbulent versus molecular diffusion
}

\author{
Lutz Lohse*, Eric H. G. Epping**, Willem Helder, Wim van Raaphorst \\ Netherlands Institute for Sea Research (NIOZ), PO Box 59, 1790 AB Den Burg, Texel, The Netherlands
}

\begin{abstract}
Oxygen pore water profiles in North Sea sediments were measured with microelectrodes during 2 contrasting seasons. The measurements were conducted in a wide variety of sediments, including non-depositional areas on the southern shelf as well as depositional areas in the Skagerrak. All measurements were performed within minutes on board at in situ temperature. The curvature of oxygen profiles in sandy sediments on the southern shelf indicated the presence of a surface layer characterised by enhanced diffusion. The occurrence of enhanced diffusion was related to sedimentological and seasonal differences. Quantitative evaluation of the pore water profiles by a diffusion-reaction model indicated that the effective diffusion coefficients in a 0.2 to $16 \mathrm{~mm}$ subsurface layer were 1.5 to $>100$ times higher than the molecular diffusion coefficient. Highest effective diffusion coefficients were reported for non-depositional sediments characterised by low diffusive oxygen fluxes. Oxygen profiles in sediments of the depositional area of the Skagerrak indicated constant diffusivity throughout the sediment column. Diffusive fluxes calculated from profiles ranged from 5.2 to $8.9 \mathrm{mmol} \mathrm{m}^{-2} \mathrm{~d}^{-1}$ in August 1991, and were between 0.8 and $6.2 \mathrm{mmol} \mathrm{m}^{2} \mathrm{~d}^{-1}$ in February 1992. Seasonal differences in sediments located in the Skagerrak area were minor. It is proposed that near-bottom tidal currents induce enhanced diffusion transport processes in the upper millimetres of the sandy sediments of the southern North Sea, while less energetic hydrodynamical conditions in the depositional area of the Skagerrak favour sediment-water exchange based on molecular diffusion only. Biogeochemical implications of the enhanced diffusivity close to the sediment-water interface are discussed.
\end{abstract}

KEY WORDS: Oxygen - Sediment-water exchange - Microelectrode Molecular diffusion Turbulent diffusion Enhanced transport Bottom shear stress

\section{INTRODUCTION}

Continental margin areas often experience a high surface productivity in a relatively shallow water column, which promotes high organic carbon fluxes to underlying sediments. The subsequent benthic mineralisation rates can be quantified by measuring the exchange of organic matter oxidants across the sediment-water interface (e.g. Devol \& Christensen 1993, Nedwell et al. 1994). Dominating transport mechanisms contributing to the sediment-water exchange of

\footnotetext{
-E-mail: lutz@nioz.nl

- Present address: Max Planck Institute for Marine Microbiology. Celsiusstraße 1, D-28359 Bremen, Germany
}

solutes are molecular diffusion (Rasmussen \& Jørgensen 1992), bioturbation and bioirrigation (Christensen et al. 1984), turbulent processes induced by the movement of the overlying water (Vanderborght et al. 1977), and advective processes caused by bioroughness of the seabed (Hüttel \& Gust 1992a). The relative importance of these processes depends on the sediment characteristics and the fauna composition, which, in turn, are controlled by the hydrodynamical regime. Generally, mass transport of solutes in the overlying water is controlled by eddy diffusion, leading to a relatively uniform distribution of dissolved material. Very close to the sediment surface, viscous forces and surface friction retard the turbulent water flow and the velocity of water approaches zero (Boudreau \& Guinasso 1982). In this region, called the diffusive 
boundary layer, eddy diffusion becomes smaller than molecular diffusion and the transport of dissolved material is dominated by molecular forces (Jorgensen \& Des Marais 1990). Near-bottom pressure fluctuations and increasing bottom shear stress decrease the thickness of the diffusive boundary layer and, thus, the resistance of solute transfer across the sediment-water interface. Finally, the replacement of pore water with overlying water results in the enhanced mixing of solutes, which may be quantified by enhanced diffusion coefficients (e.g Vanderborght et al. 1977). Advective processes can be induced by ventilating macrofauna (Aller 1982, Forster et al. 1995) and by highly turbulent water columns flushing surficial sediments by wind-induced waves or tidal currents (Riedl \& Ott 1972). As a consequence, pore water profiles of solutes exhibit irregularities which cannot be explained by usual diffusion-reaction models based on molecular transport alone.

The laboratory studies of Hüttel \& Gust (1992a) have visualised pore water flow by measuring changes in rhodamine dye distributions in pore waters. Those authors reported advective transport at moderate water flow velocities down to $1 \mathrm{~cm}$ below a smooth sediment surface and down to $20 \mathrm{~cm}$ below protruding biogenic structures. Field studies documenting pore water profiles influenced by enhanced transport are limited. Two fundamental problems arise when the curvature of affected pore water profiles and sediment-water fluxes are to be identified: First, techniques commonly applied to measure pore water components usually do not sufficiently resolve concentration gradients at the sediment-water interface. Second, the distribution of bottom friction forces created by the stirring device in confined sediment-water enclosures does not necessarily reflect the in situ flow and pressure conditions acting at the seafloor (Hüttel \& Gust 1992b). Consequently, interstitial gradients may be altered upon incubation, and the resulting flux of pore water compounds across the sediment-water interface is erroneous (Booij 1991).

Previous investigations in North Sea shelf sediments attributed wave action and tidal currents to be responsible for pore water anomalies. Vanderborght et al. (1977) concluded that the concave shape of silica pore water profiles along the Belgian coastal zone was caused by a 100-fold higher diffusion in the first $3.5 \mathrm{~cm}$ of the sediment compared to deeper layers, where molecular diffusion was the dominating transport mechanism. Similar findings were reported for intertidal areas, where tracer experiments indicated turbulent diffusion in the upper $1.5 \mathrm{~cm}$ due to tidal currents (Rutgers van der Loeff 1981). Gehlen et al. (1995) concluded that the discrepancy between calculated (assuming molecular diffusion) and measured sedi- ment-water fluxes of silicate after inactivation of macrofauna could only be explained by assuming enhanced (turbulent) diffusion induced by wave and current action.

Oxygen electrodes are particularly suited for the study of sediment-water exchange processes. By inserting them into the sediment with sub-millimeter resolution, concentration gradients can be visualised without a significant disturbance of the sediment structure. Additionally, consecutive profiling in relatively short time intervals may reveal lateral and temporal variation of the pore water profile. In this paper we report data on the micro-distribution of oxygen in continental shelf sediments of the North Sea. While previous studies at the same stations focused on nitrogen cycling (Lohse et al. 1993, 1995), we will now address the seasonal dynamics of oxygen pore water profiles in a representative selection of depositional and nondepositional sediments of the southeastern North Sea, including the Skagerrak. The profiles were obtained during the BELS-cruises (Benthic Links and Sinks in North Sea Nutrient Cycling) in August 1991 and February 1992.

\section{MATERIAL AND METHODS}

Study site. Data were obtained at 7 stations located In the southeastern and central North Sea, including the Skagerrak (Fig. 1). A comprehensive overview describing the general characteristics of the visited stations (Lohse et al. 1995) as well as data concerning phosphate, silicate, ammonium adsorption and iron/ manganese cycling are given elsewhere (Gehlen et al. 1995, Slomp et al. 1996a, b, Van Raaphorst \& Malschaert 1996). Briefly, all stations were located along the main transport route of water masses and organic matter in the North Sea (Otto et al. 1990). Water depths of the shelf stations ranged between 19 and $58 \mathrm{~m}$ (see Table 1), one station (Stn 9) was located at $330 \mathrm{~m}$ water depth in the northeastern North Sea, where the Skagerrak forms part of a larger basin system (Norwegian Trench) Net deposition has been reported only for this area (Van Weering et al. 1987) and for Stn 13 located in the inner German Bight (Von Haugwitz et al. 1988).

Coring. Sediment cores were obtained using a cylindrical boxcorer $[31 \mathrm{~cm}$ inner diameter (i.d.), $60 \mathrm{~cm}$ length] developed at the Netherlands Institute for Sea Research (NIOZ). The boxcorer was equipped with a hydraulically dampened closing lid to avoid pressure effects during core retrieval. The bottom of the boxcorer was sealed with a rubber plate during retrieval which prevented percolation of water through the sediment column. Upon retrieval, sub-cores were taken by 
acrylic liners after visual inspection of the sediment-water interface. In the case of turbid overlying water or visible cracks on the sediment surface, the boxcore was discarded. Acrylic liners were pushed into the sediment in such a way that visible biogenic structures such as funnels and burrow openings were excluded from sampling

Oxygen profiles. Within 5 to $10 \mathrm{~min}$ of ondeck securement of the boxcore, oxygen profiles were measured in a subcore $15.4 \mathrm{~cm}$ i.d., $20 \mathrm{~cm}$ length). While the core was incubated at in situ temperature in a water bath fitted with a thermostat, 2 to 6 consecutive profiles were recorded. Since the bottom shear stress varied considerably among the sedimentary settings, we decided to omit stirring at all stations. Oxygen profiles were measured with Clark-type microelectrodes (type 737. Diamond Corp.) provided with an internal reference and guard electrode (Revsbech 1989). The average tip diameter was $100 \mu \mathrm{m}$ and the electrodes provided $90 \%$ of the signal within $3 \mathrm{~s}$. Typical output at $100 \% \mathrm{O}_{2}$ saturation at ambient conditions $\left(15^{\circ} \mathrm{C}, 33 \% \mathrm{~S}\right)$ was 300 to $500 \mathrm{pA}$. The stirring effect, defined as the difference of the signal in stagnant and vigorously stirred water, was less than $2 \%$. The zero signal in anoxic sediment ranged from 8 to $15 \mathrm{pA}$. The electrodes were calibrated after the oxygen concentra-

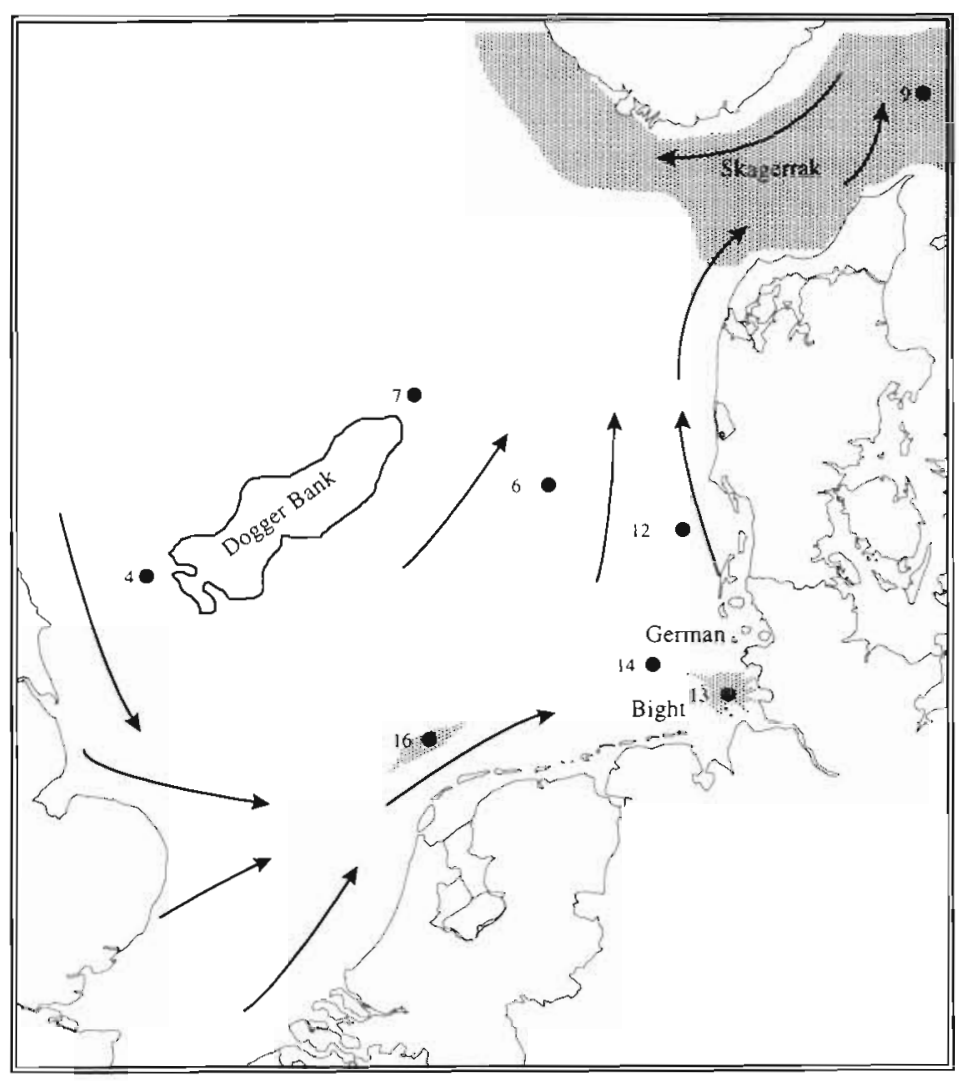

Fig. 1. Central and northeastern North Sea showing the BELS sampling sites and associated station numbers. Arrows indicate main transport routes of water and suspended matter. Shaded areas indicate maın deposition regions

$$
\frac{\partial C}{\partial t}=D_{\mathrm{s}} \frac{\partial^{2} C}{\partial z^{2}}-R
$$
tion and output was assumed (Revsbech 1989). The electrode was inserted into the sediment core at random positions in steps of 250 (around the sedimentwater interface) to $500 \mu \mathrm{m}$ (in deeper sediment layers). Consequently, the precise visual determination of the sediment-water interface was subject to a maximum uncertainty of $250 \mu \mathrm{m}$

Quantitative evaluation of the oxygen profiles was performed by modelling the profile shape according to the diffusion-reaction model of Bouldin (1968). In this model, the steady-state distribution of oxygen in aphotic sediments is governed by its consumption due to chemical and respiratory oxidation processes on the one hand and transport by molecular diffusion on the other. It is assumed that the consumption of oxygen is depth and oxygen independent. i.e. corresponding to zero-order kinetics with respect to oxygen (Hao et al. 1983). Ignoring lateral diffusion and assuming depth independent parameters, a 1-dimensional expression for transport and reaction can be formulated (Berner 1980): where $C$ denotes the oxygen concentration, $z$ denotes depth (m), $t$ denotes time (d), $R$ denotes the volumetric oxygen consumption rate $\left(\mathrm{mmol} \mathrm{m}^{-3} \mathrm{~d}^{-1}\right)$ and $D_{s}$ represents the molecular diffusion coefficient $\left(\mathrm{m}^{2} \mathrm{~d}^{-1}\right)$ corrected for sediment tortuosity:

$$
D_{s}=D_{0} \otimes^{m-1}
$$

where $D_{0}$ is the free solution diffusion coefficient corrected for temperature with the Stokes-Einstein relation (Li \& Gregory 1974), 0 is the porosity, and $m$ denotes an exponent corresponding to various types of sediment (Ullman \& Aller 1982). Accordingly, $m$ was assumed to be 3 at the clayish $\operatorname{Stn} 9$ and assumed to be 2 at all other sandy stations.

The depth-dependent concentration of oxygen in the sediment can be calculated by solving Eq. (1) according to Bouldin (1968):

$$
C(z)=\left(\frac{R}{2 D_{4}}\right) z^{2}-\left(\frac{2 C_{0} R}{D_{s}}\right) z^{2}+C_{0}
$$


where $C_{0}$ denotes the oxygen concentration in the overlying water $\left(\mathrm{mmol} \mathrm{m}^{-3}\right)$. The boundary conditions are: $C=0$ at $z_{\max }, \mathrm{dC} / \mathrm{dz}=0$ at $z_{\max }, C=C_{0}$ at $z=0$.

According to the Bouldin model, the square root of the oxygen concentration plotted against depth yields a straight line in which the slope equals $\sqrt{(R / 2 D)}$ (Booij et al. 1991). However, most profiles plotted in this way showed considerable deviation from a straight line (data not shown), indicating that a constant $R / D$-ratio may not be valid. As has been proposed by Vanderborght et al. (1977) and Booij et al. (1991), we assume that the upper part of the oxygen profile is governed by enhanced diffusive transport. In order to account for this phenomenon, we divided the oxic zone into 2 discrete sublayers where each layer has its own diffusion coefficient (Vanderborght et al. 1977). This approach simplifies the complexity of enhanced mixing processes but allows quantification of the different mixing rates in both layers. A higher coefficient $\left(D_{1}\right)$ is assumed in the zone ranging from the sediment surface to $z_{1}$, while molecular diffusion holds in the second layer ranging from $z_{1}$ to $z_{\max }$. The corresponding diffusion-reaction equations for both layers become:

$$
\begin{array}{lll}
\text { Layer I } & 0<z \leq z_{1} & \frac{\partial C_{1}}{\partial t}=D_{1} \frac{\partial^{2} C_{1}}{\partial z^{2}}-R \\
\text { Layer II } & z_{1}<z \leq z_{\max } & \frac{\partial C_{2}}{\partial t}=D_{s} \frac{\partial^{2} C_{2}}{\partial z^{2}}-R
\end{array}
$$

At $z=z_{1}$, the additional boundary conditions become:

$$
\begin{aligned}
C_{1}\left(z_{1}\right) & =C_{2}\left(z_{1}\right) \\
D_{1} \frac{\mathrm{d} C_{1}}{\mathrm{~d} z} & =D_{\mathrm{s}} \frac{\mathrm{d} C_{2}}{\mathrm{~d} z}
\end{aligned}
$$

The depth-dependent oxygen concentration can be calculated by solving the differential equations, Eqs (4) $\&(5)$ :

$$
C_{1}(z)=\frac{R}{2 D_{1}} z^{2}-\frac{R_{z_{\max }}}{D_{1}} z+C_{0}
$$

$$
\begin{aligned}
C_{2}(z) & =\frac{R}{D_{\mathrm{s}}}\left(\frac{z^{2}-z_{1}^{2}}{2}-z_{\max }\left(z-z_{1}\right)\right) \\
& +\frac{R_{z_{1}}}{D_{1}}\left(\frac{z_{1}}{2}-z_{\max }\right)+C_{0}
\end{aligned}
$$

The sediment-water flux $\left(J_{0}\right.$, in $\left.\mathrm{mmol} \mathrm{m} \mathrm{m}^{-2} \mathrm{~d}^{-1}\right)$ follows from.

$$
J_{0}=ø R z_{\max }
$$

The model fit procedure was carried out using the Microsoft Excel solver routine, calculating the parameters $C_{0}, R, z_{1}$ and $D_{1}$ at the minimum value of the sum of squares between experimental and modelled oxygen concentrations.

Porosity, organic carbon/nitrogen and grain size analysis. All methods applied to determine these parameters are summarised in previous papers (Lohse et al. 1993, 1995). Briefly, porosity determinations were based on weight loss of the known aliquots of sediment before and after drying at $60^{\circ} \mathrm{C}$ for $48 \mathrm{~h}$. Sedimentary organic carbon content was measured according to Verardo et al. (1990). A grain size analysis was performed for the upper $0.5 \mathrm{~cm}$ of the sediment using a laser-diffraction-size analyser (Malvern $2600 \mathrm{E}$ ), following the procedure of McCave et al. (1986). Samples were pre-treated with $\mathrm{HCl}$ and $\mathrm{H}_{2} \mathrm{O}_{2}$ in order to remove carbonates and organic matter.

\section{RESULTS}

\section{Oxygen and temperature in bottom water}

The variation in bottom water temperature between

\begin{tabular}{|c|c|c|c|c|c|c|c|c|c|}
\hline \multirow[t]{2}{*}{ Stn } & & \multirow{2}{*}{$\begin{array}{c}\text { Latitude } \\
\left({ }^{\circ} \mathrm{N}\right)\end{array}$} & \multirow{2}{*}{$\begin{array}{l}\text { Longitude } \\
\left.\qquad{ }^{\circ} \mathrm{E}\right)\end{array}$} & \multirow{2}{*}{$\begin{array}{l}\text { Depth } \\
(\mathrm{m})\end{array}$} & \multicolumn{2}{|c|}{ Temperature $\left({ }^{\circ} \mathrm{C}\right)$} & \multicolumn{2}{|c|}{$\left[\mathrm{O}_{2}\right]_{\mathrm{BW}}\left(\mathrm{mmol} \mathrm{m}^{-3}\right)$} & \multirow{2}{*}{$\begin{array}{c}\text { Organic } \\
(\%)\end{array}$} \\
\hline & & & & & Aug & Feb & Aug & Feb & \\
\hline 9 & Skagen & 58.20 & 10.27 & 330 & 6.9 & 7.0 & 276 & 313 & 2.78 \\
\hline 13 & German Bight & 54.05 & 08.09 & 19 & 18.7 & 4.4 & 196 & 353 & 1.28 \\
\hline 16 & Frisian Front & 53.42 & 04.32 & 39 & 17.4 & 6.3 & 232 & 327 & 0.46 \\
\hline 6 & Weiss Bank & 55.17 & 06.00 & 49 & 12.2 & 5.8 & 227 & 337 & 0.16 \\
\hline 7 & Tail End & 56.00 & 04.38 & 50 & 9.5 & 6.1 & 230 & 333 & 0.16 \\
\hline 14 & Elbe Rinne & 54.14 & 07.20 & 39 & 16.5 & 5.4 & 186 & 329 & 0.46 \\
\hline 12 & Esbjerg & 55.12 & 07.38 & 25 & 17.7 & 4.8 & 241 & 345 & 0.06 \\
\hline 4 & Dogger Bank & 54.20 & 01.00 & 58 & 8.2 & 6.4 & 267 & 326 & 0.12 \\
\hline
\end{tabular}
stations was larger in August than in February (Table 1). In August, the most shallow stations had the highest temperatures, while in February these stations had the lowest temperatures. Differences between periods were negligible at the deepest station, Stn 9, in

Table 1. Position, depth, bottom water temperature, dissolved oxygen concentration $\left(\left[\mathrm{O}_{2}\right]_{\mathrm{B} w}\right)$ and organic carbon content of stations 


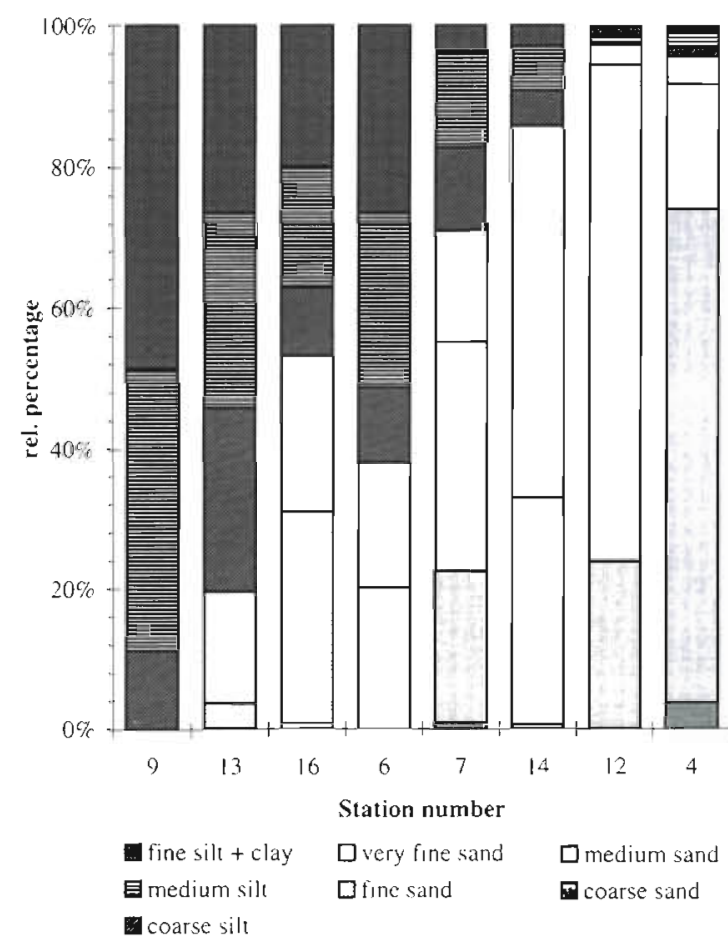

Fig. 2. Contribution of grain size classes to sediment composition

the Skagerrak. Dissolved oxygen concentrations in the water column indicated a slight under saturation in August at most stations (Table 1). Lowest oxygen concentrations were found at Stns $14\left(186 \mathrm{mmol} \mathrm{m}^{-3}\right)$ and $13\left(196 \mathrm{mmol} \mathrm{m}^{-3}\right)$, corresponding to saturations of 75 and $82 \%$, respectively. In February, all dissolved oxygen concentrations in the water column were close to saturation

\section{Sediment column characteristics}

According to the Udden-Wentworth scale of sediment classification, medium silts prevailed at Stns 9 and 13, while very fine (Stns 6, 14 and 16) and fine sands (Stns 7 and 12) characterised the other sedimentary settings. Coarsest sediment was found at Stn 4 (medium sand). A more detailed picture is given by the relative contributions of different size fractions to the bulk sediment (Fig, 2). Corresponding to findings in previous investigations, the grain size composition documented here reflects the hydraulic regime in the North Sea (Wiesner et al. 1990)

Organic carbon contents were negatively correlated with grain size. Highest contents of organic carbon were found at Stns 9 (medium grain size: $20 \mu \mathrm{m}$ ) and $13(82 \mu \mathrm{m})$, while very low contents occurred at Stns 12 $(188 \mu \mathrm{m}), 7(143 \mu \mathrm{m})$ and $4(296 \mu \mathrm{m})$. Down-core con- centrations did not differ substantially from values at the sediment-water interface. At Stns 9, 13 and 16 , organic carbon and the specific surface area of the mineral fraction were analysed by L. M. Mayer, University of Maine, ME, USA. All organic carbon concentrations fell within the proposed monoequivalent-layer of sorbed organic carbon to mineral grains, suggesting that the organic carbon concentrations found in these North Sea sediments are entirely controlled by the surface area of the mineral fraction (Mayer 1994)

Porosity profiles are given in Fig. 3. Values at the sediment-water interface ranged between 0.90 (Stn 9) and 0.44 (Stn 4). Down-core porosities were between 30 (Stn 6$)$ and $9 \%(\operatorname{Stn} 9)$ lower than the surface values.

\section{Oxygen profiles}

The curvature of oxygen profiles indicates strong seasonal differences in most of the investigated North Sea sediments. Lower oxygen penetrations were found in August 1991 compared to February 1992 (Fig. 4). In August, apparently anoxic sediments were found at Stns 12, 13 and 14 in the German Bight area. Here, oxygen concentrations had already started to decrease in the unstirred water column of the sediment cores and reached zero values within the upper $250 \mu \mathrm{m}$ just above the sediment-water interface. Most likely, these oxygen profiles are caused by a combination of the release of reduced compounds into the overlying water and the absence of a turbulent water column.

At the other stations oxygen penetrated between 2.9 (Stn 6) and $11.1 \mathrm{~mm}$ (Stn 9) into the sediment. In February, the oxic zone in all sediments had extended to values between 0.5 (Stn 13) and $\sim 45 \mathrm{~mm}$ (Stn 4). Minor differences between the 2 months were measured in the Skagerrak (Stn 9). Due to technical problems, no oxygen profiles could be obtained at Stn 4 in August.

Several oxygen profiles displayed a more or less distinct transition boundary separating 2 contrasting oxygen gradients within the sediment. The gradient in the upper zone was always less steep than the gradient found in the lower layer (Fig. 4). The appearance of this transition boundary was correlated with seasonal variations as well as to site-specific sediment characteristics. In August, the transition was close to the sediment-water interface and absent at Stns 12, 13 and 14 (all anoxic). Moreover, the differences in slope above and below the transition boundary were less pronounced than in February, when this layer had moved deeper into the sediment. This is particularly exemplified at Stns 4, 7 and 12 , which hardly showed an oxygen decrease in Layer I, followed by a sudden increase in slope.

Sediment characteristics were inversely correlated with the presence of this transition zone. Coarsest sed- 


\section{Porosity}
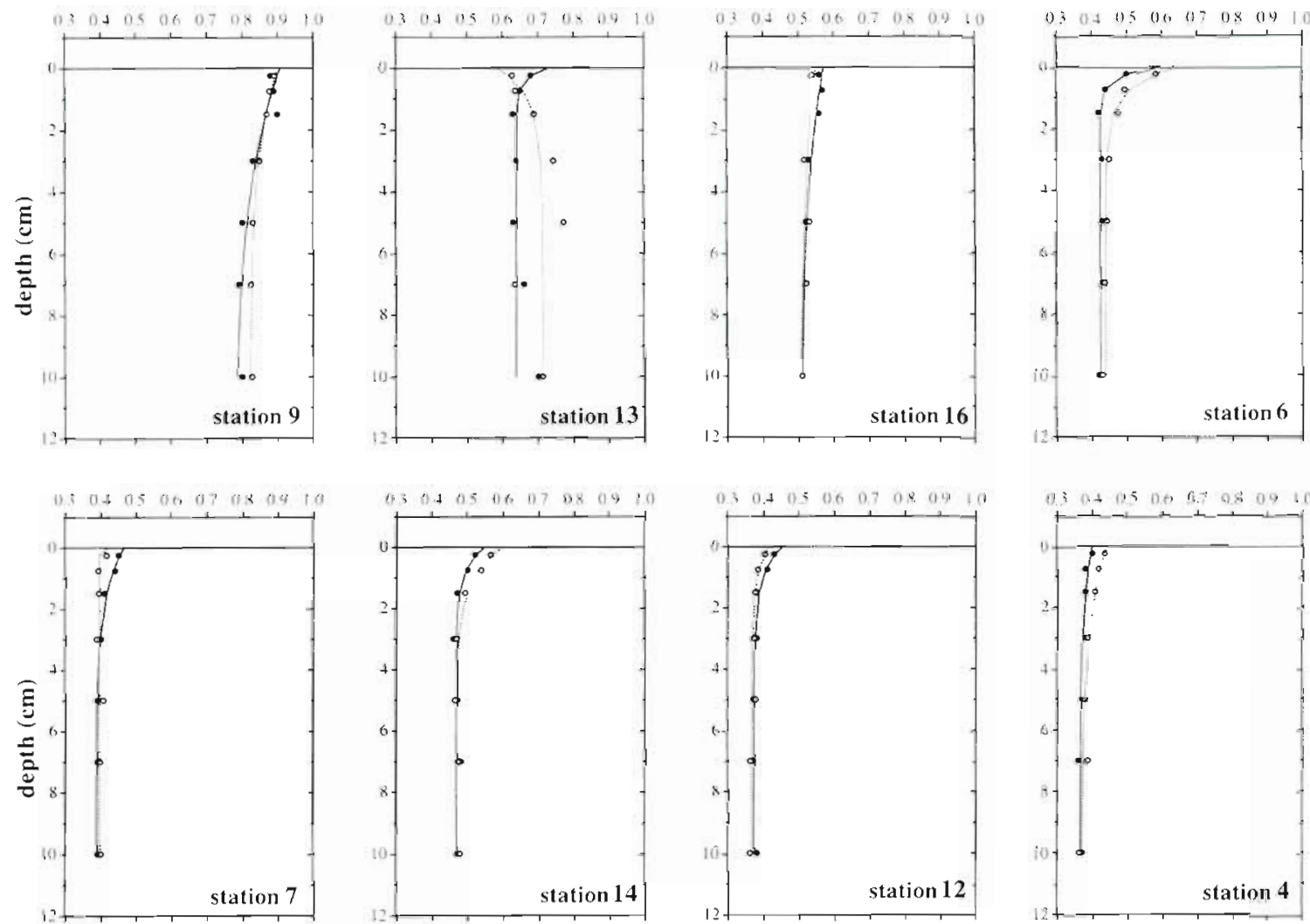

Fig. 3. Porosity profiles in August $1991(\bullet)$ and February $1992(0)$. Lines were fitted according to $\left[\theta=\theta_{\infty}+\left(\theta-\theta_{\infty}\right) e^{-(\alpha, z}\right]$, where $\theta_{\infty}$ represents constant porosity at depth, $\emptyset_{0}$ represents the porosity at the sediment-water interface, $\alpha$ is a constant and $z$ is depth

iments (Stns 4 and 12) showed the most pronounced differences in oxygen gradients. More regular oxygen profiles were recorded at $\operatorname{Stn} 9$, where high percentages of clay and silt particles dominated the grain size spectrum.

Sensitivity of the model and fitting procedure

The 2-layer model yielded reasonable fits, indicating that the oxygen profiles can be described by an enhanced diffusion coefficient $\left(D_{i}\right)$ in the upper layer, compared to molecular diffusion coefficients $\left(D_{\mathrm{s}}\right)$ prevailing in the lower layer (Fig 4). However, several model constraints have to be taken into account before the derived parameters can be discussed.

High residuals (here defined as differences between experimental and fit values) around the transition zone from enhanced to molecular diffusion indicate that this region is not confined to a discrete boundary $\left(z_{1}\right)$, as assumed in the model, but rather spans several millimeters (Fig 5). The residuals showed a larger deviation from the measured profile below $z_{1}$, possibly indi- cating that the assumption of a constant respiration throughout the oxic zone is not entirely warranted (e.g. Mackin \& Swider 1989, Epping \& Helder unpubl.). We assumed the respiration rate to be constant throughout the oxic zone, since other approaches did not substantially improve the fit

Two other aspects of the fitting procedure must be addressed. The fitting procedure incidentally identifies a transition boundary, $z_{1}$, although visual inspection of the profiles does not support its existence. This shortcoming was evident at Stn 16 in February, where the model defined small-scale scatter around $7 \mathrm{~mm}$ depth as the transition boundary. To establish an objective criterion to distinguish between such small scale variability and the best estimate of $z_{1}$, we fixed $z_{1}$ to variable values spanning $25 \%$ around the optimal value found by the fitting procedure. For each fixed $z_{1}$ value, $R, C_{0}$, and $D_{1}$ were optimised and the resulting sum of least squares was plotted against the fixed $z_{1}$ values (Fig 6). In February, a deviation of $\pm 10 \%$ from the optimal $z_{1}$ values resulted in a $60 \%$ increase of the sum of least squares at $\operatorname{Stn} 12$, while at $\operatorname{Stn} 16$ a similar $10 \%$ deviation amounted to only a $10 \%$ increase. We inter- 


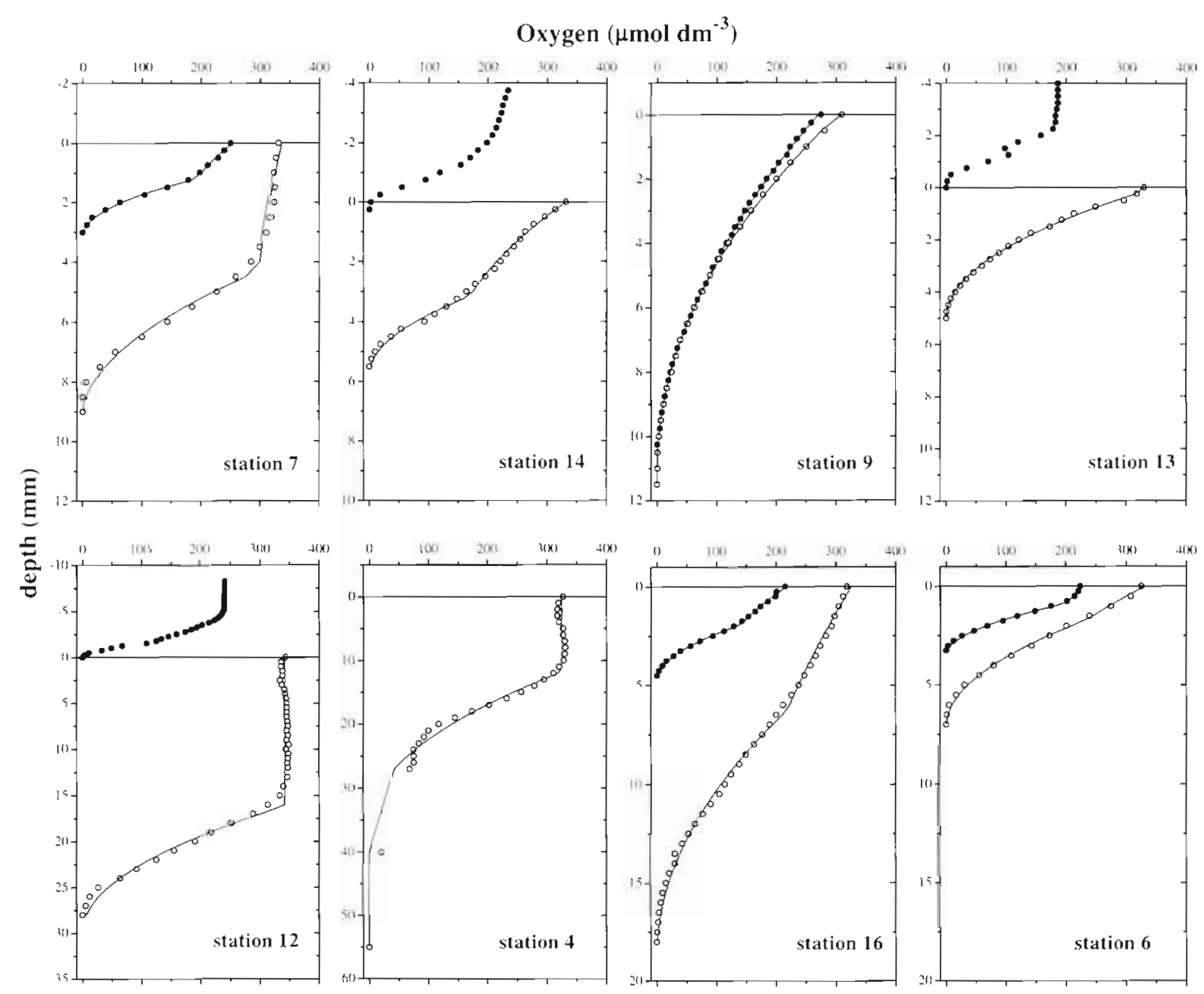

Fig. 4. First oxygen profiles at the investigated stations in August $(\bullet)$ and February (0). Solid line indicates model fit (see text) Note difterences in depth scale

pret the increase in the sum of squares $\leq 20 \%$ after a $10 \%$ in shift in $z_{1}$ as not significant. From this criterion, the estimations of $z_{1}$ at $\operatorname{Stn} 9$ in August and February and at Stn 16 in February are considered as not significant with regard to the scatter of the data.

The opposite situation existed in those profiles where oxygen hardly decreased in Layer I, but was followed by an abrupt decrease in Layer II (Stns 4 and 12 in February), clearly suggesting the presence of a boundary at $z_{1}$. At these stations, the model provided extremely high $D_{1}$ values of 139 and $12.4 \mathrm{~m}^{2} \mathrm{~d}^{-1}$ (note, values are not $\times 10^{-5}$ ), respectively. These values were due to the insensitivity of the model to increasing $D_{1}$ above a certain value, resulting in no further decrease of the sum of squares when the diffusion coefficient in Layer I $\left(D_{1}\right)$ exceeded the molecular diffusion coefficient $\left(D_{\mathrm{s}}\right)$ by a factor of $>100$. Consequently, the high $D_{1}$ values at Stns 4 and 12 in February should only be interpreted as $>100 \times D_{\mathrm{s}}$.

\section{Estimated diffusion coefficients}

$D_{\mathrm{s}}$ values ranged between $6.0 \times 10^{-5}$ and $11.0 \times$ $10^{-5} \mathrm{~m}^{2} \mathrm{~d}^{-1}$ in August and had decreased to $4.5 \times$ $10^{-5}$ to $10.9 \times 10^{-5} \mathrm{~m}^{2} \mathrm{~d}^{-1}$ in February (Table 2) In August, significantly enhanced diffusion could only be estimated at Stns 6,7 and 16 , where $D_{1}$ reached values between $16.8 \times 10^{-5}$ and $32.6 \times 10^{-5} \mathrm{~m}^{2} \mathrm{~d}^{-1}$. Considerably higher values were estimated in February, ranging between $10.6 \times 10^{-5}$ (Stn 6) and $480 \times$ $10^{-5} \mathrm{~m}^{2} \mathrm{~d}^{-1}(\mathrm{Stn} 4)$. In this period, highest $D_{1}$ was found at Stns 4 and 12, both having the most coarse grain size spectrum. The model output produced $D_{1}$ values more than 100 times higher than $D_{s}$. At other stations, $D_{1} / D_{\text {s }}$ ranged between 1.5 (Stn 6) and 18.7 (Stn 7). As mentioned before, significant differences between $D_{1}$ and $D_{\mathrm{s}}$ were not discernible at the finegrained Stn 9 in either season or at Stn 16 in February. 


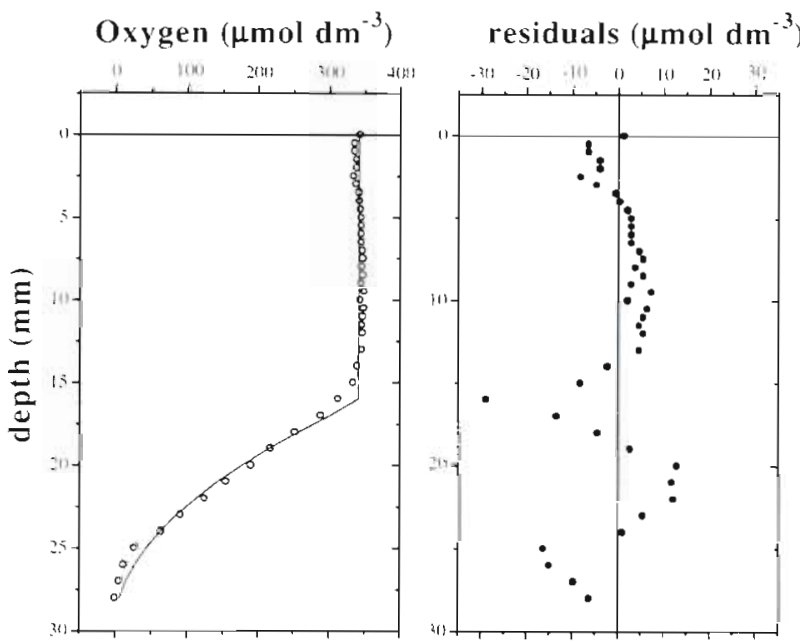

Fig. 5. Example of a fitted oxygen profile (Stn 12, February) and the corresponding residuals. For explanation see text

Diffusive fluxes across the sediment-water interface and volumetric oxygen consumption

Diffusive axygen fluxes $\left(J_{0}\right)$ across the sedimentwater interface showed marked seasonal and spatial variations. With the exception of $\operatorname{Stn} 9$, where no significant differences between seasons were detected, estimated fluxes in August were 4 times higher than those estimated in February (Table 2). In August, highest fluxes were detected at the apparently anoxic Stns 12,13 and 14 with $28.4,23.7$ and $24.8 \mathrm{mmol} \mathrm{m}^{-2}$ $\mathrm{d}^{-1}$, respectively, obtained by fitting a straight line

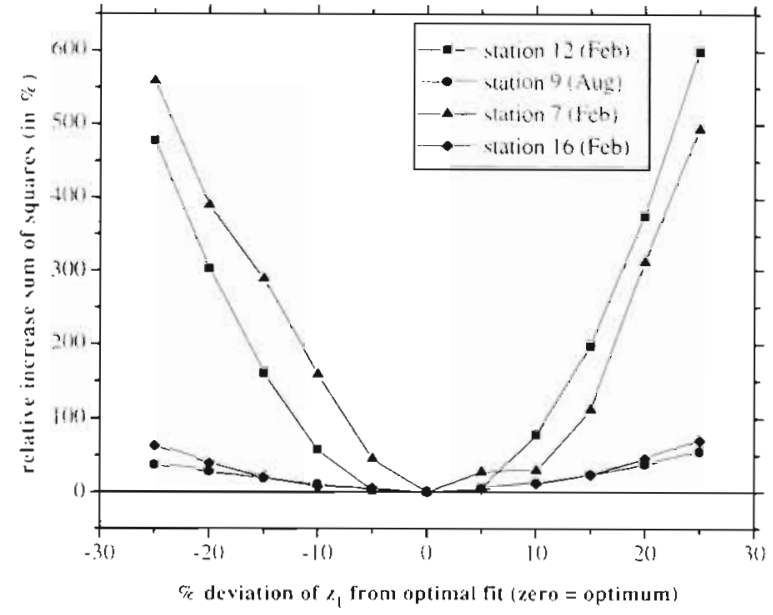

Fig. 6. Examples of increase of sum of squares after fixing $z_{1}$ to depths ranging between $\pm 25 \%$ of the optimal value. For explanation see text

through the linear part of the profile above the sediment-water interface and using the free solution diffusion coefficient according to Broecker \& Peng (1977). Fluxes at other stations ranged between 5.2 and $8.9 \mathrm{mmol} \mathrm{m} \mathrm{m}^{-2} \mathrm{~d}^{-1}$. In February, oxygen fluxes dropped by a factor of between 1.3 (Stn 6) and 5 (Stn 14), resulting in fluxes between 0.8 and $6.2 \mathrm{mmol} \mathrm{m}^{-2} \mathrm{~d}^{-1}$ The most pronounced seasonal difference was found at Stn 12, where the oxygen flux in February had decreased by a factor of 15 compared to August.

Model-derived volumetric oxygen consumption rates $(R)$ were highest at Stns 6 and 7 in August, where

Table. 2. Model outputs and derived parameters in August 1991 (A) and February 1992 (F). $z_{1}$ : depth to which turbulent diffusion occurs; $z_{\max }$ : depth at which boundary conditions $C=0$ and $\mathrm{d} C / \mathrm{d} z=0$ are met; $D_{1}$ and $D_{5}$ : diffusion coefficients for $0<z \leq z_{1}$ and $z_{3}<z \leq z_{\max }$, respectively; $R$ : volumetric oxygen consumption rate $J_{z=0}$ : diffusive oxygen flux at the sediment-water interface. Values in parentheses indicate non-significant values (see text)

\begin{tabular}{|c|c|c|c|c|c|c|c|}
\hline Station & $\begin{array}{l}D_{s} \\
\left(10^{-5}\right.\end{array}$ & $\begin{array}{r}D_{1} \\
\left.\mathrm{~A}^{-2} \mathrm{~d}^{-1}\right)\end{array}$ & $D_{1} / D_{\mathrm{s}}$ & $z_{1}$ & $(\mathrm{~mm})^{z_{\max }}$ & $\begin{array}{c}R \\
\left(\mathrm{mmol} \mathrm{m}^{-3} \mathrm{~d}^{-1}\right)\end{array}$ & $\begin{array}{c}J_{z=0} \\
\left(\mathrm{mmol} \mathrm{m} \mathrm{m}^{-2} \mathrm{~d}^{-1}\right)\end{array}$ \\
\hline $4 \mathrm{~F}$ & 4.8 & $>480$ & $>100$ & 11.8 & 35.6 & 21 & 0.8 \\
\hline $6 \mathrm{~A}$ & 7.2 & 16.8 & 2.3 & 0.5 & 2.9 & 2388 & 6.9 \\
\hline $6 \mathrm{~F}$ & 70 & 10.6 & 1.5 & 2.2 & 6.3 & 850 & 5.3 \\
\hline $7 \mathrm{~A}$ & 6.0 & 31.6 & 5.3 & 1.2 & 3.1 & 2865 & 8.9 \\
\hline $7 \mathrm{~F}$ & 5.1 & 94.8 & 18.7 & 4.3 & 9.3 & 517 & 4.8 \\
\hline $9 \mathrm{~A}$ & 11.0 & $(12.4)$ & $(1.1)$ & (5.2) & 11.1 & 469 & 5.2 \\
\hline $9 F$ & 10.9 & $(0.01)$ & $(1.0)$ & 0.0 & 11.0 & 481 & 5.3 \\
\hline $12 \mathrm{~A}$ & $17.0^{\mathrm{d}}$ & - & - & - & $<0.25$ & - & 28.4 \\
\hline $12 \mathrm{~F}$ & 4.5 & $>450$ & $>100$ & 16.2 & 29.8 & 64 & 1.9 \\
\hline $13 \mathrm{~A}$ & $17.5^{\circ}$ & - & - & - & $<0.25$ & - & 23.7 \\
\hline $13 \mathrm{~F}$ & 7.1 & 24.6 & 3.4 & 0.2 & 5.0 & 1244 & 6.2 \\
\hline $14 \mathrm{~A}$ & $16.5^{d}$ & - & - & - & $<0.25$ & - & 24.8 \\
\hline $14 \mathrm{~F}$ & 6.6 & 23.7 & 3.6 & 0.6 & 5.7 & 887 & 5.0 \\
\hline $16 \mathrm{~A}$ & 9.3 & 32.6 & 3.5 & 1.4 & 5.0 & 1307 & 6.7 \\
\hline $16 \mathrm{~F}$ & 6.6 & $(16.8)$ & $(2.6)$ & (6.3) & 18.7 & 100 & 1.9 \\
\hline
\end{tabular}


they amounted to 2388 and $2865 \mathrm{mmol} \mathrm{m}^{-3} \mathrm{~d}^{-1}$, respectively (Table 2). At Stns 9 and 16, estimates of 469 and $1307 \mathrm{mmol} \mathrm{m} \mathrm{m}^{-3} \mathrm{~d}^{-1}$, respectively, were obtained. In February, all rates dropped by a factor of between 3 (Stn 6) and 13 (Stn 16). Comparatively low rates were modelled at Stns 4 and 12. As for diffusive oxygen fluxes, seasonal differences in volumetric oxygen consumption were negligible at $\operatorname{Stn} 9$.

\section{DISCUSSION}

Our dataset demonstrates the impact of wave- or current-induced hydrodynamic forces on the diffusive exchange of oxygen across the sediment-water interface. Physical enhancement of solute transport in permeable, marine sediments has been explained by advective processes (Hüttel \& Gust 1992a) and turbulent diffusion (Vanderborght et al, 1977). Both advection and turbulent diffusion may have contributed to the observed shape of oxygen profiles. For instance, advective flow in permeable sediments may induce turbulent diffusion as a result of pressure gradients generated around protruding biogenic structures. Also, 2 adjacent water parcels driven by these pressure gradients through the sediment pores may choose different pathways around the sediment particles. The differential path lengths cause dispersion and the resulting concentration gradient of a solute is smeared out to an extent greatly exceeding that predicted on the basis of molecular diffusion (Bear 1972, Harrison et al. 1983). Rotating pressure gradients may result in an even more effective dispersion of solutes by mixing them with their new surroundings before the pressure gradient reverses (Webster \& Taylor 1992). All these processes may have contributed to the enhanced diffusion observed in the sandy North Sea sediments. For simplicity and because, at least for rotational dispersion, it has been demonstrated that the enhanced mixing can be modelled as a random diffusion-type process, we followed the approach of Webster \& Taylor (1992) by introducing an enhanced diffusion coefficient in an upper, subsurface sediment layer.

Hydrodynamical and sedimentological conditions may allow for pore water motion in subsurface layers of southern North Sea sediments. The permeability of sediments in this area derived from grain size and porosity (Chilingar 1964) ranges from 20 (Stn 13) to 150 darcy (Stn 4), whereas bottom friction velocities ranged between 1 and $7 \mathrm{~cm} \mathrm{~s}^{-1}$ depending on location and tidal phase (Jago et al. 1994, Pohlmann \& Puls 1994). The bottom water flow was also investigated by underwater video images, which revealed a maximum speed of suspended particles just above the seafloor between 5 to $20 \mathrm{~cm} \mathrm{~s}^{-1}$ (L. Lohse pers. obs., Jenness \&
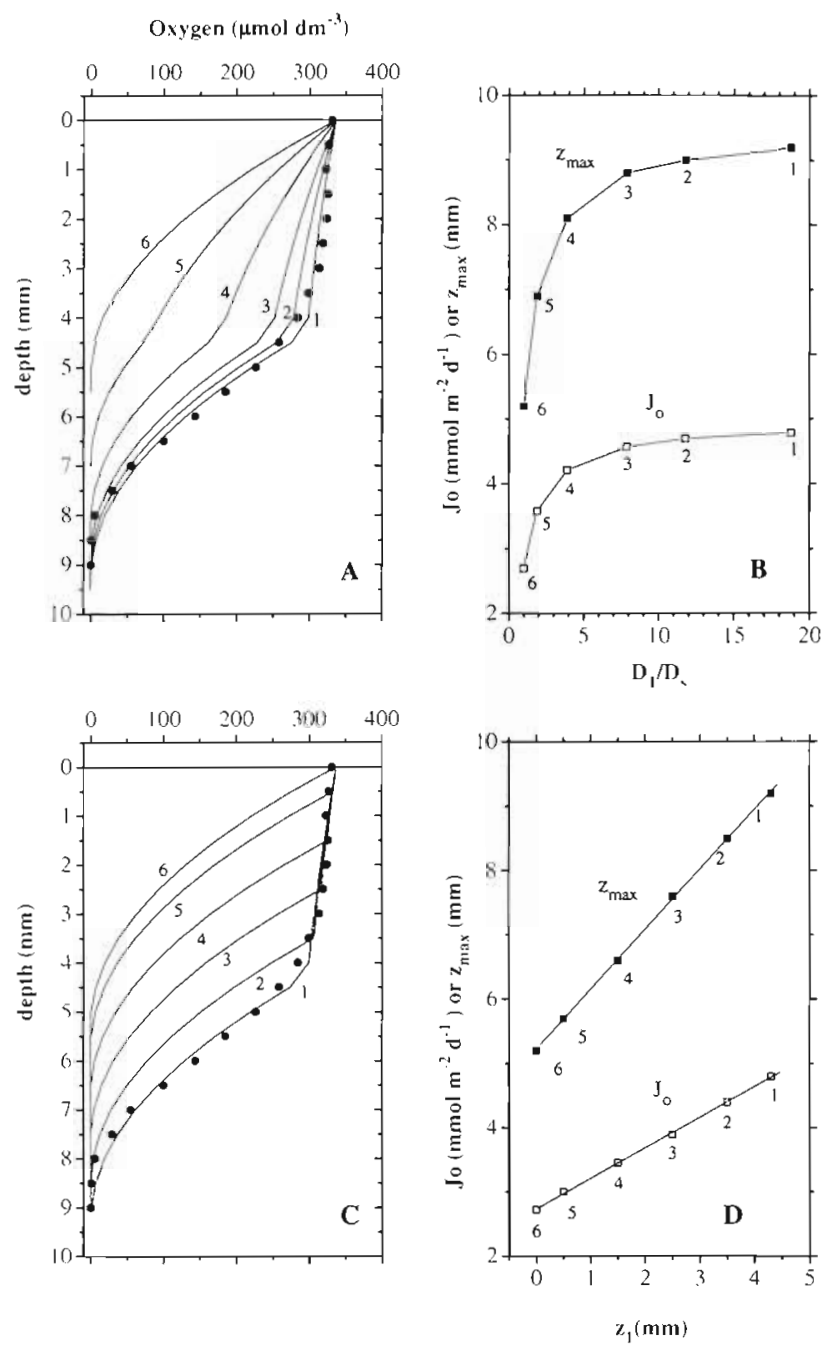

Fig. 7. (A) Effect of stepwise reduction of the ratio $D_{1} / D_{5}$ from 19 to 1 on the shape of oxygen pore water profiles; (B) oxygen fluxes across the sediment-water interface $\left(J_{0}\right.$, a $)$ and the penetration depth $\left(z_{\max },-\right)$. (C) Effect of stepwise reduction of $z_{1}$ from 4.3 to $0 \mathrm{~mm}$ on oxygen pore water profiles; (D) oxygen fluxes across the sediment-water interface $\left(J_{0}, 0\right)$ and the penetration depth $\left(z_{\max }, \boldsymbol{e}\right)$. Circles indicate the first measured profile recorded at $\operatorname{Stn} 7$ in February

Duineveld 1985). These hydrodynamical and bulk sediment characteristics are comparable to those found in laboratory studies in which unidirectional, advective flow affected the upper centimeters of permeable subsurface sediments (Hüttel \& Gust 1992a).

In order to evaluate the effect of enhanced diffusion on the oxygen distribution in sediments we can produce theoretical oxygen profiles in which (1) the ratio $D_{1} / D_{\mathrm{s}}$ is step-wise decreased, so that finally $D_{1}$ equals $D_{\mathrm{s}}$ (Fig. 7A), and (2) the depth of $z_{1}$ is step-wise reduced to $z=0$ (Fig. $7 \mathrm{C}$ ). Both procedures lead to an oxygen profile entirely governed by molecular diffusion. The volumetric oxygen consumption rate $(R)$ and the oxygen concentration in the overlying water $\left(C_{0}\right)$ 
were kept constant while the changes in flux $\left(J_{0}\right)$ and penetration depth $\left(z_{\max }\right)$ were calculated. Initial values for $D_{1} / D_{s}$ and $z_{1}$ were taken from the fitted profile at Stn 7 in February (Table 2). Decreasing ratios of $D_{1} / D_{3}$ from 19 to 1 reduced the oxygen flux by $56 \%$ (Fig. 7B). In the same interval, $z_{\max }$ declined from 9.3 to $5.2 \mathrm{~mm}$. Both $z_{\mathrm{mux}}$ and $J_{0}$ showed a nearly logarithmic response to increasing $D_{1} / D_{\text {s }}$ ratios when $z_{1}$ remained constant at a depth of $4.3 \mathrm{~mm}$. Such an logarithmic response was not found when $z_{1}$ was decreased (Fig 7D) at a constant $D_{1} / D_{\mathrm{S}}$ of 19 . In that simulation, $z_{\max }$ and $J_{0}$ responded linearly to an upward shift of $z_{1}$ Thus, calculated maximum penetration depths and the oxygen fluxes are most sensitive to an increase of the $D_{1} / D_{s}$ ratio from 1 to $\sim 5$. At higher ratios the effect of a change of $z_{1}$ becomes more important.

The exclusion of water flow during boxcore retrieval and non-stirring conditions during the electrode measurements result in an adaptation of the oxygen profile. Plotting the oxygen profiles obtained at every station in a consecutive sequence reveals that such a shift was indeed observed (Fig. 8). With increasing incubation time after core retrieval, $z_{1}$ and $z_{\max }$ tended to shift towards the sediment surface, as would be expected from the absence of enhanced diffusion in the upper millimeters. Assuming that each oxygen profile represents a steady-state situation with the respective hydrodynamic condition, we can model transient oxygen profiles. This reveals that $z_{1}$ at $\operatorname{Stn} 7$ in February decreased from $4.3 \mathrm{~mm}$ in the first profile to $2.3 \mathrm{~mm}$ in the fourth profile, accompanied by a decrease of the maximum oxygen penetration from 9.3 to $7.3 \mathrm{~mm}$. Correspondingly, the modelled sediment-water flux $\left(J_{0}\right)$ decreased by $36 \%$ from 4.8 to $3.1 \mathrm{mmol} \mathrm{m}^{-2} \mathrm{~d}^{-1}$ during the incubation time. Similar trends, although less pronounced, are derived from the analysis of oxygen profiles at $\operatorname{Stn} 16$, where $z_{1}$ from 1.4 to $0.4 \mathrm{~mm}$. The diffusive oxygen flux at this particular station decreased by $32 \%$, while a decrease of up to $54 \%$ was observed at $\operatorname{Stn} 4$. These percentages can be considered as minimum estimates since the first and the last profile represent transient states, resembling neither the initial in situ profile at the seafloor nor the final oxygen profile affected by molecular diffusion only.

The time between subsequent profiles in Fig. 8 , including profiling, withdrawal and repositioning of the electrode, amounted to a period of between 10 and 15 min at Stn 16 in August. Extrapolating the period between the profiles suggests that the effect of initial enhanced diffusive transport mechanism will be eliminated within 30 to 60 min after boxcore retrieval. Similar findings were reported by Booij et al. (1991), who studied the response of oxygen profiles to abrupt changes in the bottom friction velocity in sandy sediments. In these sediments the period necessary to achieve a new steady-state oxygen concentration after the decrease in friction velocity amounted to $\sim 30 \mathrm{~min}$ at a depth of $2 \mathrm{~mm}$. When the friction velocity was increased, the oxygen concentration reached its steadystate concentration within $<1$ min. This asymmetric response was explained by the predominance of advective transport over molecular diffusion and sediment oxygen consumption. When advective processes are eliminated, molecular diffusion and the respiratory consumption of oxygen will induce shifts in oxygen gradients. At Stn 16 in August, the depth-integrated oxygen decrease between individual profiles amounted to $\sim 2200 \mathrm{mmol} \mathrm{m}^{-3} \mathrm{~d}^{-1}$, which is in the same order of magnitude as the modelled volumetric oxygen consumption of $1307 \mathrm{mmol} \mathrm{m} \mathrm{m}^{-3} \mathrm{~d}^{-1}$ (Table 2). The absence of pronounced shifts at Stn 12 in February (data not shownl is in line with the very low volumetric oxygen consumption modelled here. Clearly, the combination of molecular diffusion and the volumetric oxygen consumption rate determine how fast an oxygen profile adapts to stagnant flow conditions.

The curvature of oxygen profiles can be reasonably modelled by assuming 1.5- to 100 -fold-higher effective diffusion coefficients in the subsurface Layer I compared to molecular diffusion in the deeper Layer II. Although the accurrence of turbulent diffusion has marginally been recognised (Revsbech et al. 1980 . King et al. 1990), it has not been the subject of extensive field investigations. In a laboratory study, Booij et al. (1991) determined the influence of different bottom shear stress velocities on the curvature of oxygen profiles. These authors report effective diffusion coefficients between $17.3 \times 10^{-5}$ and $173 \times 10^{-5} \mathrm{~m}^{2} \mathrm{~d}^{-1}$, which

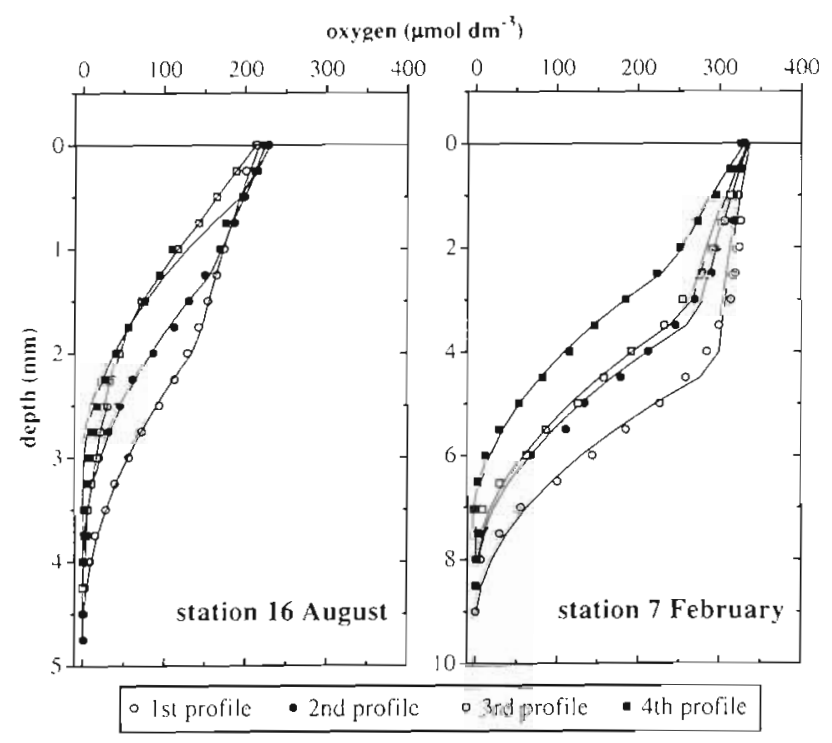

Fig. 8. Complete sets of oxygen profiles at Stns 16 (August) and 7 (February) plotted in sequential order. Note differences in depth scale 
are on the same order of magnitude as the $D_{1}$ values calculated in this study.

A possible artefact when working with permeable, sandy sediments is the risk of percolation of overlying water through the sediment column. Potential leakage of the boxcore after on-deck securement may falsify pore water gradients, which would lead to initially similar concentrations in the interstitial and the overlying water. A first impression is that this may have occurred at Stns 4 and 12, where the oxygen concentrations in the upper 12 to $16 \mathrm{~mm}$ were almost identical to the values found in the overlying water. If these gradients were caused by percolation, between 500 and $600 \mathrm{ml}$ of pore water should have leaked out of the sealed bottom site of the boxcore concomitant with a decreasing water level inside the boxcore. This was, however, never observed. Moreover, percolation should also affect other pore water components. Nitrate and ammonium pore water profiles (Fig. 9) obtained from subcores of the same boxcore (for details see Lohse et al. 1995) are in line with the established geochemical sequence of interstitial compounds as observed in many previous studies (e.g Froehlich et al. 1979). Nitrate pore water concentrations immediately below the sediment-water interface were higher than those in the overlying water, thus providing additional evidence that percolation did not interfere with our measurements.

\section{Biogeochemical implications}

Our findings may have implications for the measurement of solute exchange in confined sediment-water systems. The accuracy of such measurements relies on the similarity of the hydrodynamic conditions inside the chamber to those at the seafloor (Buchholtz-ten Brink et al. 1989, Glud et al. 1995). The technical problems involved in creating homogeneous bottom shear stresses inside a benthic chamber have already been addressed (Hüttel \& Gust 1992b). Even more complicated is the maintenance of an advective flow field and turbulent diffusion in a confined benthic chamber as found in high energetic shelf seas. Since most stirring regimes in benthic chambers do not account for these flow conditions, it is likely that molecular diffusion may be re-established, particularly with long incubation times, thus leading to underestimates of the in situ oxygen fluxes.

Our data suggest that the oxygen distribution in permeable North Sea sediments are affected by tidal currents. Ticial motion is the dominant hydrodynamical feature in the North Sea and has a strong impact on the distribution and sedimentation of organic and inorganic matter (Otto et al. 1990). Variations in bottom shear stress induced by the tidal currents interacting with the microtopography of the seabed may cause an upward and downward moving anoxic-oxic boundary. Deepest oxygen penetrations due to high enhanced transport in the upper layer will occur during maximum ebb and flood currents. Low currents during slack tide will cause the anoxic-oxic boundary to move towards the sediment-water interface. Due to reasons outlined above, the adaptation to low flow conditions occurs slowly while maximum ebb or flood currents induce immediately enhanced mixing in the upper sediment layers. This scenario implies that fluxes and penetration of oxygen are not only dependent on the sedimentary characteristics and the water flow, but also on the tidal phase. This becomes particularly obvious during the summer months, when high respiratory activity counterbalances the effect of turbulent transport processes, so that any delay between sampling and analysis may mask the appearance of enhanced transport processes (see previous discussion section).

Fluctuating anoxic-oxic boundaries and redox conditions will affect biogeochemical cycles substantially. Nitrogen cycling may be influenced by increased nitrification rates due to the temporal dispersion of oxygenrich pore water into ammonium-rich, suboxic sediment layers. This, in turn, may stimulate denitrifying activity and lead to close coupling between both processes at the oxic-anoxic boundary (Lohse et al. 1996). Subsequent thinning oxic layers may result in decreased activity of coupled nitrification-denitrification due to ammonium depletion in the oxic sediment zone (Fig. 9). Additionally, the ammonium pore water pool may be diluted by advective transport as well. Contrary to this scenario is a situation in which nitrate from

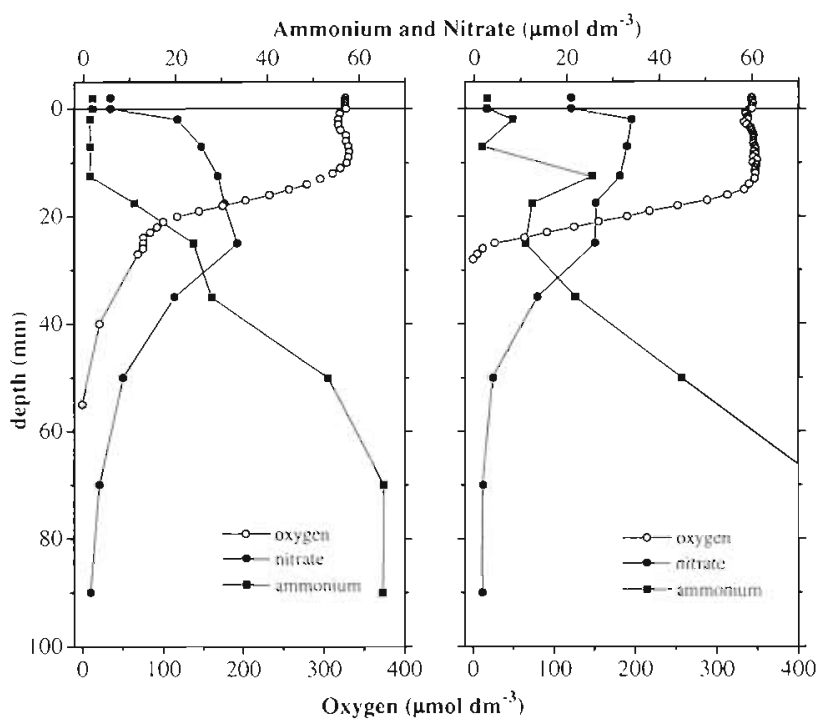

Fig. 9. Pore water profiles of ammonium, nitrate and oxygen at Stns 4 (left) and 12 (right) in February 
the overlying water is the predominating nitrate source for denitrification. Then, extended oxic layers function as a diffusional barrier between the denitrification site and the overlying water (Christensen et al. 1990). However, it is unclear to what extent this situation will be counterbalanced by the turbulent transport of nitrate into the sediment.

Cycles of other redox-sensitive elements, such as manganese and iron, and probably silicate (Vanderborght et al. 1977), may also be affected (M. Gehlen, C. Rabouille \& W van Raaphorst unpubl.). The link between biological variables and enhanced transport processes of solutes in the sediment is difficult to establish. However, data on bacterial biomass and production measured during the BELS cruises showed a positive correlation to the occurrence of enhanced advective solute transport. It appeared that the depth attenuation of bacterial production (Van Duyl \& Kop 1994) was less pronounced at stations with the highest $D_{1} / D_{\text {s }}$ ratios. Similar correlations with the abundance of heterotrophic nanoflagellates reported by Hondeveld (1994) could be established. It must be mentioned that these correlations were only discernible in August, when microbial activity was highest. This may indicate that a combination of physical factors and food availability controls the microbial food web in North Sea sediments.

\section{Conclusions}

Bottom shear stress induced by tidal currents or wave action substantially affects biogeochemical cycles in permeable continental shelf sediments. While molecular diffusion is the prevailing transport process in deep-sea and continental slope sediments, sediment-water exchange rates on the exposed continental shelf sediments may be accelerated by enhanced diffusion induced by high bottom friction velocities. Although the effect of biologically mediated pore water flow on organic matter degradation has been recognised, much less attention has been paid to turbulent diffusion initiated by physical processes This is due to the difficulty in resolving pore water anomalies in the affected subsurface layer and the adaptation of the pore water profile to new bottom friction velocities. Confined sediment-water enclosures usually do not account for turbulent diffusion, so organic matter degradation rates may be underestimated severely. As a consequence, the frequently observed inconsistency between low benthic oxygen consumption rates and the organic carbon production in the overlying water column of continental shelf seas may be less pronounced than previously thought. This, in turn, calls into question the magnitude of off-shelf carbon trans- port as hypothesised in order to elucidate the organic carbon budget in continental margin areas (Wollast 1993). Clearly, the impact of advective processes on biogeochemical rates and biological processes requires further examination

Acknowledgements. The authors thank the captain and the crew of the RV 'Pelagia' for a pleasant and safe journey. Special thanks are due to Eduard Bos for technical assistance and boxcoring under all conditions. Adri Sandee (NIOO-CEMO, Yerseke) performed the grain size analysis. This research was supported by the Netherlands Marine Research Foundation (former NWO-SOZ, grant no. 39104). This is publication no. 3018 of the Netherlands Institute for Sea Research (NIOZ).

\section{LITERATURE CITED}

Aller RC (1982) The effects of macrobenthos on chemical properties of marine sediment and overlying water. In: McCall PL, Tevesz MJS (eds) Animal-sediment relations. Plenum Publishing Corporation, New York, p 53-102

Bear J (1972) Dynamics of fluids in porous media. Elsevier, New York

Berner RA (1980) Early diagenesis. Prunceton Unıversity Press. New York

Boolj K. Helder W. Sundby B (1991) Rapid redistribution of oxygen in a sandy sediment induced by changes in the flow velocity of the overlying water. Neth J Sea Res 28 $149-165$

Boudreau BP, Gumasso NL (1982) The influence of a diffusive sublayer on accretion, dissolution and diagenesis at the sea floor. In: Fanning KA, Mannheim FT (eds) The dynamic environment of the ocean floor. Lexington Books, Toronto, p 115-145

Bouldin DR (1968) Models for describing the diffusion of oxygen and other mobile constituents across the mud-water interface. J Ecol 56:77-87

Broecker WS, Peng TH (1977) Gas exchange rates between air and sea. Tellus 26:21-35

Buchholtz-ten Brink MR, Gust G, Chavis D (1989) Calibration and performance of a stirred benthic chamber. Deep Sea Res 36:1083-1101

Chilungar GV (1964) Relation between porosity, permeability and grain size distribution of sands and sandstones. In: Van Straaten LMJU (ed) Deltaic and shallow marine deposits. Elsevier, Amsterdam, p 71-75

Chnstensen JP, Devol AH, Smethie WM (1984) Biological enhancement of solute exchange between sediments and water on the Washington continental shelf. Cont Shelf Res $3: 9-23$

Christensen PB, Nielsen LP, Sorensen J, Revsbech NP (1990) Denitrification in nitrate-rich streams: diumal and seasonal variation related to benthic oxygen metabolism Limnol Oceanogr 35:640-651

Devol. AH, Christensen JP (1993) Benthic fluxes and nutrogen cycling in sediments of the continental margin of the eastern. North Pacific. J Mar Res 51:345-372

Forster S, Graf G, Kitlar J, Powilleit M (1995) Effects of bioturbation in oxic and hypoxic conditions: a microcosm experiment with a North Sea sediment community. Mar Ecol Prog Ser 116:153-161

Froelich PN, Klinkhammer GP, Bender ML, Luetdke NA, Heath GR, Cullen D, Dauphin P, Hammond D, Hartmann B. Maynard V(1979) Early oxidation of organic matter in pelagic sediments of the eastern equatorial Atlantic: sub- 
oxic diagenesis. Geochim Cosmochim Acta 43:1075-1090

Gehlen M, Malschaert JFP, Van Raaphorst W (1995) Spatial and temporal variability of benthic silica fluxes in the southeastern North Sea. Cont Shelf Res 15:1675-1696

Glud RN, Gundersen JK, Revsbech NP, Jørgensen BB, Hüttel $M$ (1995) Calibration and performance of the stirred flux chamber from the benthic lander ELINOR. Deep Sea Res 42:1029-1042

Hao OJ, Richard MG, Jenkıns D (1983) The half saturation coefficient for dissolved oxygen: a dynamic method for its determination and its effect on dual species competition. Biotechnol Bioeng 25:403-416

Harnson WD, Musgrave D, Reeburgh WS (1983) A waveinduced transport process in marine sediments. J Geophys Res 88:7617-7622

Hondeveld BJM, Nieuwland G, Van Duyl FC, Bak RPM (1994) Temporal and spatial variations in heterotrophic nanoflagellates abundance in North Sea sediments. Mar Ecol Prog Ser 109:235-243

Hüttel M, Gust G (1992a) Impact of bioroughness on interfacial solute exchange in permeable sediments. Mar Ecol Prog Ser 89:253-267

Hüttel M. Gust G (1992b) Solute release mechanisms from confined sediment cores in stirred benthic chambers. Mar Ecol Prog Ser 82:187-197

Jago CF, Bale AJ, Green MO, Howarth MJ, Jones SE, MCCave IN, Millward GE, Morris AW, Rowden AA, Williams JJ (1994) Resuspension processes and seston dynamics, southern North Sea. In: Charnock H, Dyer KR, Huthnance $J M$, Liss PS, Simpson JH, Tett PB (eds) Understanding the North Sea system. Chapman, London, p 97-113

Jenness MI, Duineveld GCA (1985) Effects of tidal currents on chlorophyll a content of sandy sediments in the southern North Sea. Mar Ecol Prog Ser 21:283-287

Jorgensen BB, Des Marais DJ (1990) The diffusive boundary layer of sediments: oxygen gradients over a microbial mat. Limnol Oceanogr 35:1343-1355

King GM, Charlton RG, Sawyer TE (1990) Anaerobic metabolism and oxygen distribution in the carbonate sediments of a submarine canyon. Mar Ecol Prog Ser 58:275-285

Li YH, Gregory S (1974) Diffusion of ions in sea water and in deep sea sediments. Geochim Cosmochim Acta 38: $703-714$

Lohse L, Kloosterhuis HT, van Raaphorst W, Helder W (1996) Denitrification rates as measured by the isotope pairing method and by the acetylene inhibition technique in continental shelf sediments of the North Sea. Mar Ecol Prog Ser 132:169-179

Lohse L, Malschaert JFP, Slomp CP, Helder W, van Raaphorst W (1993) Nitrogen cycling in North Sea sediments: interaction of denitrification and nitrification in offshore and coastal areas. Mar Ecol Prog Ser 101:283-296

Lohse L, Malschaert JFP, Slomp CP, Helder W, van Raaphorst W (1995) Sediment-water fluxes of inorganic nitrogen compounds along the transport route of organic matter in the North Sea. Ophelia 41:173-197

Mackin JE, Swider KT (1989) Organıc matter decomposition pathways and oxygen consumption in coastal marine sediments. J Mar Res 47:681-716

Mayer LM (1994) Surface area control of organic carbon accumulation in continental shelf sediments. Geochim Cosmorhim Acta 58:1271-1284

McCave IN. Bryant RJ, Cook HF, Coughanowr CA (1986) Evaluation of a laser-diffraction-size analyser for use with natural sediments. J Sediment Petrol 56:561-564
Nedwell DB, Parkes RJ, Upton AC, Assinder DJ (1994) Seasonal fluxes across the sediment-water interface, and processes within sediments. In: Charnock $H$, Dyer KR, Huthnance JM, Liss PS, Simpson JH, Tett PB (eds) Understanding the North Sea system. Chapman, London, p $141-206$

Otto L, Zimmerman JTF, Furnes GK, Murk M, Saetre R, Becker G (1990) Review of the physical oceanography of the North Sea. Neth J Sea Res 26:161-238

Pohlmann T, Puls W (1994) Currents and transport in water In: Sündermann J (ed) Circulation and contaminant fluxes in the North Sea. Springer. Berlin, p 345-402

Rasmussen H, Jorgensen BB (1992) Microelectrode studies of seasonal oxygen uptake in a coastal sediment: role of molecular diffusion. Mar Ecol Prog Ser 81:289-303

Revsbech NP (1989) An oxygen microsensor with a guard electrode. Limnol Oceanogr 34:474-478

Revsbech NP, Sørensen J, Blackburn TH, Lomholt JP (1980) Distribution of oxygen in marine sediments measured with microelectrodes. Limnol Oceanogr 25:403-411

Riedl RJ, Ott JA (1972) Water movement through porous sediments. In: Fanning KA, Mannheim FT (eds) The dynamic environment of the ocean floor. Lexington Books, Toronto, p $29-55$

Rutgers van der Loeff MM (1981) Wave effects on sediment water exchange in a submerged sand bed. Neth J Sea Res 15:100-112

Slomp CP, Malschaert JFP, Lohse L, van Raaphorst W (1996b) Iron and manganese cycling in different sedimentary environments of the North Sea continental margin. Cont Shelf Res (in press)

Slomp CP, Van der Gaast SJ, van Raaphorst W (1996a) Phosphorus binding by poorly crystallıne iron oxides in North Sea sediments. Mar Chem (in press)

Ullman WJ, Aller RC (1982) Diffusion coefficients in nearshore marine sediments. Limnol Oceanogr 27:552-556

Vanderborght JP, Wollast R, Billen G (1977) Kinetic models of diagenesis in disturbed sediments. Part I. Mass transfer properties and silica diagenesis. Limnol Oceanogr 22: $787-793$

Van Duyl FC, Kop AJ (1994) Bacterial production in North Sea sediments: clues to seasonal and spatial variation. Mar Biol 120:323-337

Van Raaphorst W, Malschaert JFP (1996) Ammonium adsorption in superficial North Sea sediments. Cont Shelf Res 16: $1415-1435$

Van Weering TCE, Berger GW, Kalf J (1987) Recent sediment accumulation rates in the Skagerrak, northeastern North Sea. Neth J Sea Res 21:177-189

Verardo DJ, Froelich PN, McIntyre A (1990) Determination of organic carbon and nitrogen in sediments using the Carlo Erba Na-1500 analyzer. Deep Sea Res 37:157-165

Von Haugwitz W, Wong HG, Sage U (1988) The mud area southeast of Helgoland: a seismic study. Mitt Geol-Palont Inst Univ Hambg 65:409-422

Webster [T, Taylor JH (1992) Rotational dispersion in porous media due to fluctuating flows. Wat Resour Res 28: $109-119$

Wiesner MG, Haake B, Wirth $H$ (1990) Organic facies of surface sediments in the North Sea. Org Geochem 15: $419-432$

Wollast R (1993) Interactions of carbon and nitrogen cycles in the coastal zone. In: Wollast R, Mackenzie FT, Chou L (eds) Interactions of $\mathrm{C}, \mathrm{N}, \mathrm{P}$ and $\mathrm{S}$ biogeochemical cycles and global change. Springer, Berlin, p 195-210 